\title{
Intrathecal injection of magnesium sulfate: shivering prevention during cesarean section: a randomized, double- blinded, controlled study
}

\author{
Seyed Hamid Reza Faiz, Poupak Rahimzadeh, Farnad Imani, and Ali Bakhtiari
}

Department of Anesthesiology and Pain Medicine, Rasoul-Akram Medical Center, Tehran University of Medical Sciences, Tehran, Iran

Background: Regional anesthesia is known to significantly impair thermoregulation and predispose patients to hypothermia. We hypothesized that the addition of an intrathecal injection of magnesium sulfate $\left(\mathrm{MgSO}_{4}\right)$ to bupivacaine would improve perioperative shivering in female patients undergoing elective caesarean section.

Methods: In a block-randomized, double-blinded, controlled trial 72 patients scheduled for elective caesarean section with spinal anesthesia were separated into two groups. In the treatment group, $2 \mathrm{ml}$ of $0.5 \%$ bupivacaine plus $25 \mathrm{mg}$ $\mathrm{MgSO}_{4}(0.5 \mathrm{ml})$ were injected intrathecally, and in the control group $2 \mathrm{ml}$ of $0.5 \%$ bupivacaine plus $0.5 \mathrm{ml}$ normal saline were injected intrathecally. Core temperature was measured before and after drug injection at predetermined intervals. Sedation was graded using the Ramsay sedation scale.

Results: No significant intergroup differences in appearance of shivering were seen immediately or at 5, 30, 40, 50, 60, and 90 min after block administration. However, at 10, 15, and 20 min post block, there was a significant difference in shivering. The group administered $\mathrm{MgSO}_{4}$ showed lower shivering grades compared with the control group. Core temperature was significantly reduced in the $\mathrm{MgSO}_{4}$ group compared to the normal saline group 30 min after blocking. Conclusions: Intrathecal injection of $\mathrm{MgSO}_{4}$ improved perioperative shivering in female patients undergoing elective caesarean section. (Korean J Anesthesiol 2013; 65: 293-298)

Key Words: Bupivacaine, Cesarean section, Magnesium sulfate, Shivering.

Received: January 25, 2013. Revised: 1st, February 14, 2013; 2nd, March 15, 2013. Accepted: April 15, 2013.

Corresponding author: Poupak Rahimzadeh, M.D., Department of Anesthesiology and Pain Medicine, Rasoul-Akram Medical Center, Tehran University of Medical Sciences, Tehran 14455-364, Iran. Tel: 98-21-64359, Fax: 98-21-66509059, E-mail: p-rahimzadeh@tums.ac.ir

(c) This is an open-access article distributed under the terms of the Creative Commons Attribution Non-Commercial License (http:// creativecommons.org/licenses/by-nc/3.0/), which permits unrestricted non-commercial use, distribution, and reproduction in any medium, provided the original work is properly cited. 


\section{Introduction}

Shivering is a common post-anesthetic complication occurring in up to $56.7 \%$ of patients undergoing spinal or epidural anesthesia. Shivering may interfere with electrocardiogram, blood pressure, and oxygen saturation monitoring. In addition, shivering increases oxygen consumption, carbon dioxide production, and metabolic rate by up to $400 \%$. Thus, it may result in problems in patients with low cardiac and pulmonary reserves [1-3]. Preventing shivering could therefore result in better postoperative outcomes or reduce the incidence of post-surgical complications.

Magnesium sulfate $\left(\mathrm{MgSO}_{4}\right)$ has anti-shivering effects. Moreover, it has potential neuroprotective effects, and may enhance neuroprotection against the effects of hypothermia [1,3-9]. Intrathecal $\mathrm{MgSO}_{4}$ administration provides effective perioperative analgesia and can prolong the period of anesthesia and sensory blockade without any additional side-effects [4-10]. However, most of the research on the role of $\mathrm{MgSO}_{4}$ in the prevention of shivering has focused on intravenous infusion of this drug $[11,12]$. Few clinical trials have examined the effect of adding intrathecal $\mathrm{MgSO}_{4}$ to anesthetic agents such as bupivacaine to suppress anesthesia-related shivering in patients.

Similar to infusion studies, we hypothesized that the addition of intrathecal injection of $\mathrm{MgSO}_{4}$ to bupivacaine would improve perioperative shivering in female patients undergoing elective caesarean section. Few previous studies evaluated neuroaxial anti-shivering effects of intrathecal magnesium and none evaluated the anti-shivering effect of intrathecal $\mathrm{MgSO}_{4}$. Therefore, we elected to use the lowest dosage ( $25 \mathrm{mg} \mathrm{MgSO}_{4}$ ) that was formerly utilized for investigation of analgesic effects $[5,7,10]$.

\section{Materials and Methods}

In a randomized, double-blinded controlled trial, 72 patients in an academic general hospital between June 2011 and March 2012 were enrolled in the study. The patients were selected by block randomization into two groups. The inclusion criteria were as follows: 18-37 years of age and American Society of Anesthesiologists (ASA) physical status I-II who were scheduled for elective repeat cesarean section under spinal anesthesia. The exclusion criteria were as follows: ASA physical status $>$ II, obesity (body mass index $>30 \mathrm{~kg} / \mathrm{m}^{2}$ ), preoperative temperature $>38^{\circ} \mathrm{C}$, any contraindications to regional anesthesia, allergy to the study drugs, pre-eclampsia, alcohol or substance use, neuropathies, respiratory distress, coagulopathies, and any possible thermoregulation altering medications. The hospital Ethics Committee approved the study protocol and written informed consent was obtained from all participants.

Operating room temperature was maintained at $23-25^{\circ} \mathrm{C}$ with a humidity of $55-65 \%$. No other warming device was used.
Intravenous fluids fluids were preheated at room temperature. All patients were covered with one layer of surgical drapes over the chest, thighs, and calves during the operation, and one cotton blanket over the entire body postoperatively. Before administering spinal anesthesia, standard monitoring was established and patients were given $10 \mathrm{ml} / \mathrm{kg}$ lactated Ringer's solution intravenously over $30 \mathrm{~min}$.

Spinal anesthesia was administered in the left lateral decubitus position at the L4-L5 interspace. All participants received $2 \mathrm{ml}$ of $0.5 \%$ bupivacaine (Mylan, $20 \mathrm{mg} / 4 \mathrm{cc}$ ) using a Quincke spinal needle (K-3 Point, 25 G, 90 mm, Dr.Japan, Co., Tokyo, Japan). The syringes were prepared by a separate colleague and the anesthetist was not aware of the contents. In the treatment group, $2 \mathrm{ml}$ of $0.5 \%$ bupivacaine plus $25 \mathrm{mg} \mathrm{MgSO}_{4}\left(\mathrm{MgSO}_{4}\right.$ $5 \%$ diluted to $25 \mathrm{mg} / 0.5 \mathrm{ml}$, Samen daru, Iran) were injected intrathecally. In the control group, $2 \mathrm{ml}$ of $0.5 \%$ bupivacaine plus $0.5 \mathrm{ml}$ normal saline were injected intrathecally. All variables were recorded by a different colleague who was not aware of the group allocation. Core temperature was measured using an infrared tympanic electronic thermometer (Genius II, Covidien, Mansfield, MA, USA). Heart rate (HR) was measured by ECG monitoring. Systolic and diastolic blood pressures were measured by non-invasive blood pressure, and oxygen saturation by pulse oximetry. Vital signs were assessed every $5 \mathrm{~min}$ for the first $15 \mathrm{~min}$ and every $10 \mathrm{~min}$ thereafter until the end of recovery. Temperature measurements were performed before the spinal block, immediately after the spinal anesthesia, and then every 30 min until $1 \mathrm{~h}$ after entry into the post-anesthesia care unit.

Shivering was measured at the following time points: immediately after spinal anesthesia, and at 5, 10, 15, 20, 30, 40, 50, 60 and $90 \mathrm{~min}$ later. Shivering was graded where 0 (none) = no visible shivering or muscular tonicity; 1 (mild) = mild increase in masseter or face muscle tonicity; 2 (moderate) $=$ tremor or muscular tonicity in proximal muscles; and 3 (severe) $=$ tremor or muscular tonicity involving the whole body [13].

Sedation was graded using the Ramsay sedation scale, in which 1 = patient was anxious, agitated or restless; 2 = patient was co-operative, oriented, and tranquil; 3 = patient responded to commands only; 4 = patient exhibited a brisk response to light glabellar tap or loud auditory stimulus; 5 = patient exhibited a sluggish response to light glabellar tap or loud auditory stimulus; and $6=$ patient exhibited no response [14]. In cases where shivering scores were greater than or equal to 3, $25 \mathrm{mg}$ meperidine was administered intravenously. If the heart rate was less than 50 beats per min, $0.5 \mathrm{mg}$ atropine was administered. Also, if the systolic arterial pressure was less than $90 \mathrm{mmHg}$, an intravenous dose of $10 \mathrm{mg}$ ephedrine was administered.

Results were reported as means \pm standard deviation (SD) for quantitative variables and percentages for categorical variables. The groups were compared using Student's t-test for continuous 
variables and the chi-square test (or Fisher's exact test if appropriate) for the categorical variables. Trends in the changes in vital signs during the study were assessed using the trend for chisquare test. P values of 0.05 or less were considered to indicate statistical significance. All statistical analyses were carried out using SPSS version 16.0 (SPSS Inc., Chicago, IL, USA) and SAS version 9.1 for Windows (SAS Institute Inc., Cary, NC, USA).

\section{Results}

A total of 72 females with a mean age of $26.74 \pm 3.87$ (range 20-37 years), were considered for admittance into the study. They were randomized into two groups: 1) administered $\mathrm{MgSO}_{4}$ or 2) normal saline. The two groups had similar characteristics with regard to age, body mass index, sensory block onset and duration, blood loss, and duration of surgery (Table 1). Cardiorespiratory indices including systolic and diastolic blood pressures, heart rate, and $\mathrm{SpO}_{2}$ between the groups at various time points after blocking were similar $(\mathrm{P}>0.05)$ (Fig. 1 and 2).

Table 1. Demographic Data and Basal Variables of the $\mathrm{MgSO}_{4}$ and Control Groups

\begin{tabular}{lccc}
\hline \multirow{2}{*}{\multicolumn{1}{c}{ Study variable }} & \multicolumn{2}{c}{ Study group } & \\
\cline { 2 - 3 } & $\mathrm{MgSO}_{4}$ & Control & \\
\hline Age of patients & $26.22 \pm 3.78$ & $27.20 \pm 3.94$ & 0.28 \\
Body mass index & $27.92 \pm 0.88$ & $27.64 \pm 0.93$ & 0.87 \\
Operation duration & $52.08 \pm 5.77$ & $51.81 \pm 5.63$ & 0.95 \\
Sensory block duration & $80.42 \pm 4.98$ & $77.36 \pm 4.99$ & 0.44 \\
Blood loss & $252.87 \pm 63.18$ & $243.06 \pm 57.51$ & 0.50 \\
Sensory block onset & $2.49 \pm 0.69$ & $2.47 \pm 0.77$ & 0.75
\end{tabular}

All parameters are expressed as Mean \pm SD. There are no significant differences between them. $\mathrm{MgSO}_{4}$ : Magnesium sulphate.

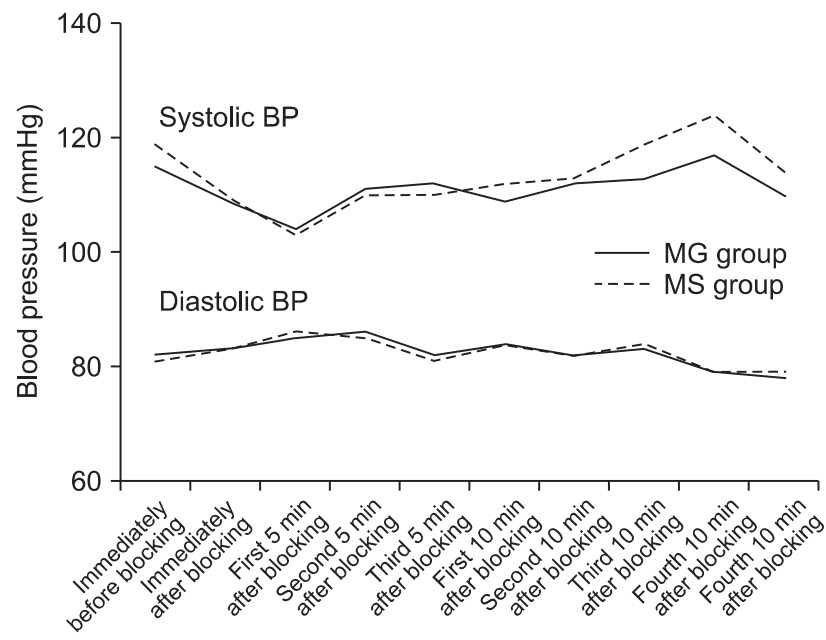

Fig. 1. Trends of systolic and diastolic blood pressure changes after blocking in the $\mathrm{MgSO}_{4}$ and control groups $(\mathrm{P}>0.05)$.
No significant intergroup differences in appearance of shivering were seen immediately, or at 5, 30, 40, 50, 60, and 90 min after block administration. However, after 10,15 , and 20 min, there was a significant difference $(\mathrm{P}<0.05)$ between the groups. The group administered $\mathrm{MgSO}_{4}$ exhibited lower shivering grades compared with the control group. No differences between the groups in the grade of sedation were observed at various time points after blocking (Table 2). Core temperature was significantly reduced in the $\mathrm{MgSO}_{4}$ group compared to the

Table 2. Sedation Rates in the $\mathrm{MgSO}_{4}$ and Control Groups

\begin{tabular}{lccc}
\hline Sedation rate & $\begin{array}{c}\mathrm{MgSO}_{4} \text { group } \\
(\mathrm{n}=36)\end{array}$ & $\begin{array}{c}\text { Control group } \\
(\mathrm{n}=36)\end{array}$ & P value \\
\hline Immediately before blocking & & & 0.55 \\
Grade 0 & $15(41.7)$ & $13(36.1)$ & \\
Grade 1 & $21(58.3)$ & $23(63.9)$ & \\
Grade 2 & $0(0.0)$ & $0(0.0)$ & \\
Immediately after blocking & & & 0.28 \\
Grade 0 & $11(30.6)$ & $7(19.4)$ & \\
Grade 1 & $25(69.4)$ & $29(80.6)$ & \\
Grade 2 & $0(0.0)$ & $0(0.0)$ & 0.22 \\
First 30 min after blocking & $2(5.6)$ & $0(0.0)$ & \\
Grade 0 & $31(86.2)$ & $33(91.7)$ & \\
Grade 1 & $1(2.8)$ & $3(8.3)$ & 0.30 \\
Grade 2 & & & \\
Second 30 min after blocking & $2(5.6)$ & $0(0.0)$ & \\
Grade 0 & $29(80.6)$ & $33(91.7)$ & \\
Grade 1 & $5(13.8)$ & $3(8.3)$ & 0.18 \\
Grade 2 & & & \\
Third 30 min after blocking & $6(16.7)$ & $9(25.0)$ & \\
Grade 0 & $26(72.2)$ & $27(75.0)$ & \\
Grade 1 & $4(11.1)$ & $0(0.0)$ & \\
Grade 2 & &
\end{tabular}

All parameters are expressed as Numbers. There are no significant differences between them. Parenthesis show percent of them (\%). $\mathrm{MgSO}_{4}$ : Magnesium sulphate.

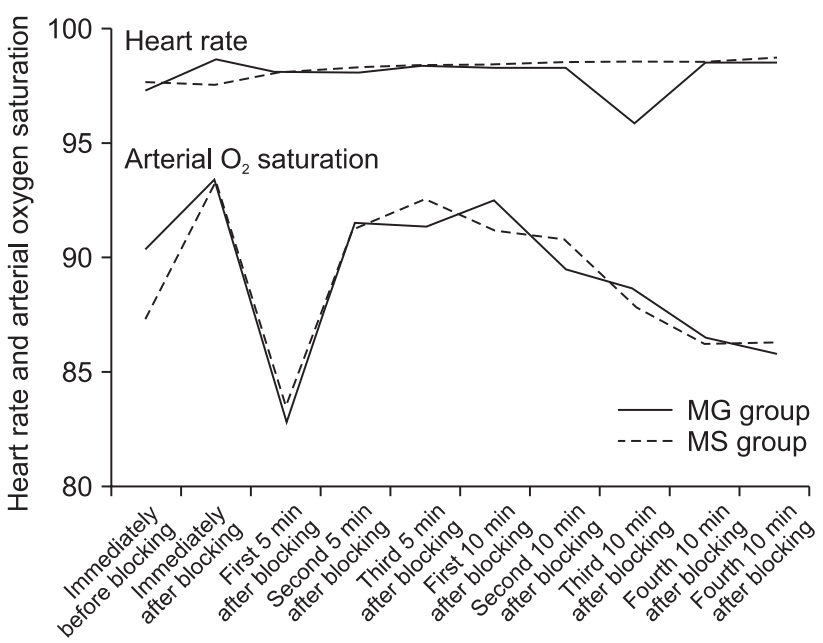

Fig. 2. Trends of heart rate and arterial oxygen saturation changes after blocking in the $\mathrm{MgSO}_{4}$ and control groups $(\mathrm{P}>0.05)$. 


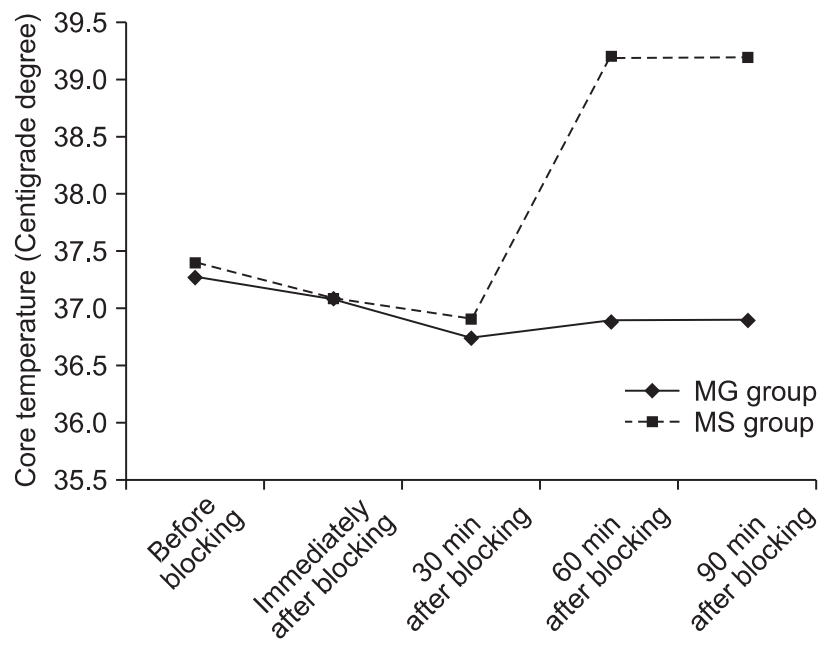

Fig. 3. Trend of core temperature changes after blocking in the $\mathrm{MgSO}_{4}$ and control groups $(\mathrm{P}<0.05$ after $30 \mathrm{~min})$.

normal saline group $30 \mathrm{~min}$ after blocking (Fig. 3). None of the patients in the $\mathrm{MgSO}_{4}$ group needed meperidine. However, 25mg meperidine was administered intravenously to eight patients $(22.2 \%)$ in the control group; the difference was statistically nonsignificant $(\mathrm{P}=0.07)$.

\section{Discussion}

Shivering may interfere with intraoperative monitoring devices and increases oxygen consumption, carbon dioxide production and lactic acidosis [3]. Research has demonstrated the effectiveness of intravenous infusion of $\mathrm{MgSO}_{4}$ in shivering control after regional anesthesia. Therefore, we evaluated its intrathecal effects in this study. There are also beneficial effects of the addition of $\mathrm{MgSO}_{4}$ to anesthetic drugs, including improving intraoperative conditions, prolongation of analgesia duration, and minimizing clinical drug-related side effects such as nausea, pruritis, and somnolence [15-18]. Indeed, $\mathrm{MgSO}_{4}$ infusion can prevent shivering during transurethral prostatectomy and lower limb surgeries in patients receiving spinal anesthesia [3,7]. However, the current study is the first to determine the effect of adding intrathecal $\mathrm{MgSO}_{4}$ to bupivacaine in patients undergoing caesarean section.

The main finding of this study is that in patients undergoing caesarean with spinal anesthesia, the addition of $\mathrm{MgSO}_{4}$ intrathecally effectively reduced shivering within 10 to 20 min after block administration. This effect, however, did not persist thereafter. Considering these findings, we presume that the injection of $2 \mathrm{ml}$ of $0.5 \%$ bupivacaine plus $25 \mathrm{mg} \mathrm{MgSO}_{4}$ intrathecally is not a sufficient dose to achieve a continuous or longer duration of anti-shivering effects. Interestingly, the shivering scores were lower in both groups after $20 \mathrm{~min}$ (Table 3).
Table 3. Appearance of Shivering after Blocking in the $\mathrm{MgSO}_{4}$ and Control Groups

\begin{tabular}{|c|c|c|c|}
\hline Time after blocking & $\begin{array}{c}\mathrm{MgSO}_{4} \text { group } \\
(\mathrm{n}=36)\end{array}$ & $\begin{array}{l}\text { Control group } \\
\quad(\mathrm{n}=36)\end{array}$ & $P$ value \\
\hline Immediately after blocking & & & 0.63 \\
\hline Grade 0 & $29(80.5)$ & $31(86.1)$ & \\
\hline Grade 1 & $6(16.7)$ & $4(11.1)$ & \\
\hline Grade 2 & $1(2.8)$ & $1(2.8)$ & \\
\hline 5 min after blocking & & & 0.23 \\
\hline Grade 0 & $27(75.0)$ & $23(63.9)$ & \\
\hline Grade 1 & $6(16.7)$ & $10(27.8)$ & \\
\hline Grade 2 & $3(8.3)$ & $3(8.3)$ & \\
\hline 10 min after blocking & & & 0.01 \\
\hline Grade 0 & $28(77.8)$ & $16(44.5)$ & \\
\hline Grade 1 & $8(22.2)$ & $17(47.2)$ & \\
\hline Grade 2 & $0(0.0)$ & $3(8.3)$ & \\
\hline 15 min after blocking & & & $<0.01$ \\
\hline Grade 0 & $32(88.9)$ & $16(44.5)$ & \\
\hline Grade 1 & $4(11.1)$ & $14(38.8)$ & \\
\hline Grade 2 & $0(0.0)$ & $6(16.7)$ & \\
\hline 20 min after blocking & & & $<0.01$ \\
\hline Grade 0 & $34(94.4)$ & $25(69.4)$ & \\
\hline Grade 1 & $2(5.6)$ & $10(27.8)$ & \\
\hline Grade 2 & $0(0.0)$ & $1(2.8)$ & \\
\hline 30 min after blocking & & & 0.10 \\
\hline Grade 0 & $33(91.6)$ & $30(83.3)$ & \\
\hline Grade 1 & $2(5.6)$ & $5(13.9)$ & \\
\hline Grade 2 & $1(2.8)$ & $1(2.8)$ & \\
\hline 40 min after blocking & & & 0.55 \\
\hline Grade 0 & $31(86.1)$ & $32(88.9)$ & \\
\hline Grade 1 & $5(13.9)$ & $4(11.1)$ & \\
\hline Grade 2 & $0(0.0)$ & $0(0.0)$ & \\
\hline 50 min after blocking & & & 0.43 \\
\hline Grade 0 & $32(88.9)$ & $33(91.6)$ & \\
\hline Grade 1 & $4(11.1)$ & $2(5.6)$ & \\
\hline Grade 2 & $0(0.0)$ & $1(2.8)$ & \\
\hline 60 min after blocking & & & 0.31 \\
\hline Grade 0 & $30(83.3)$ & $32(88.9)$ & \\
\hline Grade 1 & $4(11.1)$ & $3(8.3)$ & \\
\hline Grade 2 & $2(5.6)$ & $1(2.8)$ & \\
\hline 90 min after blocking & & & 0.27 \\
\hline Grade 0 & $32(88.9)$ & $31(86.1)$ & \\
\hline Grade 1 & $3(8.3)$ & $4(11.1)$ & \\
\hline Grade 2 & $1(2.8)$ & $1(2.8)$ & \\
\hline
\end{tabular}

All parameters are expressed as numbers. There are significant differences between them in 10, 15 and 20 minutes. $\mathrm{MgSO}_{4}$ : Magnesium sulphate.

Haulbold and Meltzer [19] reported sensorial and motor blockades in humans after intrathecal administration of magnesium. Furthermore, recent studies have demonstrated that the administration of magnesium intrathecally is safe and in combination with other anesthetic agents extends the effects of spinal anesthesia in both animal and human models [20]. The beneficial effects of $\mathrm{MgSO}_{4}$ on preventing post-anesthetic shivering, however, remain unclear. Despite the investigation of multiple drug regimens in prevention of postoperative shivering, the ideal treatment has not yet been determined. Some of these agents are as follows: meperidine, tramadol, fentanyl, physostigmine, clonidine, 
and ketamine [1,21-26]. Because the incidence of hypotension, sedation and other side effects is relatively significant following use of these drugs, administration to reduce shivering may not be ideal. Consequently, the use of regional $\mathrm{MgSO}_{4}$ is attractive for this purpose.

The mechanism of shivering during regional anesthesia is not understood. Some possibilities include a temporary halt in central thermoregulation $[1,23,24]$ and internal redistribution of body heat lost to the environment [25]. Furthermore, $\mathrm{MgSO}_{4}$ use can cause peripheral vasodilatation, which potentially improves coetaneous circulation, thus decreasing the incidence of shivering [10]. Moreover, $\mathrm{MgSO}_{4}$ acts as a calcium antagonist and a noncompetitive antagonist of N-methyl-D-aspartate receptors, and its effect on analgesia, particularly neuropathic pain symptoms and motor blockade lengthening, has been reported $[3,15,27]$. This mechanism of action has also been considered for the antishivering effects of magnesium, but requires further investigation in animal models and clinical studies.

In the current study, we also report that core temperature was reduced in the $\mathrm{MgSO}_{4}$ group 30 min after block administration. Indeed, injection of $\mathrm{MgSO}_{4}$ is known to result in reduction of core temperature following anesthesia. Gozdemir et al. [3] reported that $\mathrm{MgSO}_{4}$ infusion prevented shivering in patients receiving spinal anesthesia, but increased the risk of hypothermia. In the Wadhwa et al. [28] study, magnesium significantly reduced the shivering threshold. However, it could not induce hypothermia as a therapeutic approach. In fact, magnesium at a dose sufficient to raise the plasma concentration more than twofold only slightly suppressed thermoregulatory defenses against hypothermia compared with those treated with placebo. The shivering threshold in volunteers given magnesium decreased by only $0.3^{\circ} \mathrm{C}$ to a core temperature of $36.3^{\circ} \mathrm{C}[3,28]$. This decrease in core temperature may be mediated by the ability of $\mathrm{MgSO}_{4}$ to induce peripheral vasodilatation.

The search continues for anesthetic agents that can sufficiently enhance thermoregulatory tolerance without simultaneously producing other complications [29]. Administration of $\mathrm{MgSO}_{4}$ is a potential candidate in this field. However, our results regarding thermoregulatory effects of $\mathrm{MgSO}_{4}$ require further investigation, including studies with a larger sample size and different magnesium dosages. Perhaps then a correlation between $\mathrm{MgSO}_{4}$ thermoregulatory and shivering effects and spinal anesthesia will be discovered. The duration of anti-shivering effects may be extended by use of higher dosages. Also, we recommend recording core temperature simultaneously with shivering measurement.

\section{References}

1. Chen JC, Hsu SW, Hu LH, Hong YJ, Tsai PS, Lin TC, et al. Intrathecal meperidine attenuates shivering induced by spinal anesthesia. Ma Zui Xue Za Zhi 1993; 31: 19-24.

2. De Witte J, Sessler DI. Perioperative shivering: physiology and pharmacology. Anesthesiology 2002; 96: 467-84.

3. Gozdemir M, Usta B, Demircioglu RI, Muslu B, Sert H, Karatas OF. Magnesium sulfate infusion prevents shivering during transurethral prostatectomy with spinal anesthesia: a randomized, double-blinded, controlled study. J Clin Anesth 2010; 22: 184-9.

4. Sirvinskas E, Laurinaitis R. Use of magnesium sulphate in anesthesiology. Medicina (Kaunas) 2002; 38: 695-8.

5. Ozalevli M, Cetin TO, Unlugenc H, Guler T, Isik G. The effect of adding intrathecal magnesium sulphate to bupivacaine-fentanyl spinal anaesthesia. Acta Anaesthesiol Scand 2005; 49: 1514-9.

6. Lejuste MJ. Inadvertent intrathecal administration of magnesium sulfate. S Afr Med J 1985; 68: 367-8.

7. Khalili G, Janghorbani M, Sajedi P, Ahmadi G. Effects of adjunct intrathecal magnesium sulfate to bupivacaine for spinal anesthesia: a randomized, double-blind trial in patients undergoing lower extremity surgery. J Anesth 2011; 25: 892-7.

8. Nowak L, Bregestovski P, Ascher P, Herbet A, Prochiantz A. Magnesium gates glutamate-activated channels in mouse central neurones. Nature 1984; 307: 462-5.

9. Mayer ML, Westbrook GL, Guthrie PB. Voltage-dependent block by Mg2+ of NMDA responses in spinal cord neurones. Nature 1984; 309: 261-3.

10. Faiz SH, Rahimzadeh P, Sakhaei M, Imani F, Derakhshan P. Anesthetic effects of adding intrathecal neostigmine or magnesium sulphate to bupivacaine in patients under lower extremities surgeries. J Res Med Sci 2012; 17: 918-22.

11. Miyakawa H, Matsumoto K, Matsumoto S, Mori M, Yoshitake S, Noguchi T, et al. A comparison of three drugs (pethidine, magnesium sulfate and droperidol) in patients with post-anesthesia shivering. Masui 1991; 40: 1503-6.

12. Kizilirmak S, Karakaş SE, Akça O, Ozkan T, Yavru A, Pembeci K, et al. Magnesium sulfate stops postanesthetic shivering. Ann N Y Acad Sci 1997; 813: 799-806.

13. Vanderstappen I, Vandermeersch E, Vanacker B, Mattheussen M, Herijgers P, Van Aken H. The effect of prophylactic clonidine on postoperative shivering. A large prospective double-blind study. Anaesthesia 1996; 51: 351-5.

14. Ramsay MA, Savege TM, Simpson BR, Goodwin R. Controlled sedation with alphaxolone-alphadalone. Br Med J 1974; 2: 656-9.

15. Yousef AA, Amr YM. The effect of adding magnesium sulphate to epidural bupivacaine and fentanyl in elective caesarean section using combined spinal-epidural anaesthesia: a prospective double blind randomised study. Int J Obstet Anesth 2010; 19: 401-4. 
16. Khezri MB, Yaghobi S, Hajikhani M, Asefzadeh S. Comparison of postoperative analgesic effect of intrathecal magnesium and fentanyl added to bupivacaine in patients undergoing lower limb orthopedic surgery. Acta Anaesthesiol Taiwan 2012; 50: 19-24.

17. Malleeswaran S, Panda N, Mathew P, Bagga R. A randomised study of magnesium sulphate as an adjuvant to intrathecal bupivacaine in patients with mild preeclampsia undergoing caesarean section. Int J Obstet Anesth 2010; 19: 161-6.

18. Lee AR, Yi HW, Chung IS, Ko JS, Ahn HJ, Gwak MS, et al. Magnesium added to bupivacaine prolongs the duration of analgesia after interscalene nerve block. Can J Anaesth 2012; 59: 21-7.

19. Haubold HA, Meltzer SJ. Spinal anesthesia by Magnesium Sulphate.A report of seven operations performed under its influence. JAMA 1906; XLVI: 647-50.

20. Mebazaa MS, Ouerghi S, Frikha N, Moncer K, Mestiri T, James MF, et al. Is magnesium sulfate by the intrathecal route efficient and safe? Ann Fr Anesth Reanim 2011; 30: 47-50.

21. Gupta SD, Mitra K, Mukherjee M, Roy S, Sarkar A, Kundu S, et al. Effect of magnesium infusion on thoracic epidural analgesia. Saudi J Anaesth 2011; 5: 55-61.

22. Buggy D, Higgins P, Moran C, O'Donovan F, McCarroll M. Clonidine at induction reduces shivering after general anaesthesia. Can J Anaesth 1997; 44: 263-7.

23. Liu WH, Luxton MC. The effect of prophylactic fentanyl on shivering in elective caesarean section under epidural analgesia. Anaesthesia 1991; 46: 344-8.

24. Sutherland J, Seaton H, Lowry C. The influence of epidural pethidine on shivering during lower segment caesarean section under epidural anaesthesia. Anaesth Intensive Care 1991; 19: 228-32.

25. Kurz A, Sessler DI, Schroeder M, Kurz M. Thermoregulatory response thresholds during spinal anaesthesia. Anesth Analg 1993; 77: 721-6.

26. Ayatollahi V, Hajiesmaeili MR, Behdad S, Gholipur M, Abbasi HR. Comparison of prophylactic use of meperidine and two low doses of ketamine for prevention of post-anesthetic shivering: A randomized double-blind placebo controlled trial. J Res Med Sci 2011; 16: 1340-6.

27. Rondón LJ, Privat AM, Daulhac L, Davin N, Mazur A, Fialip J, et al. Magnesium attenuates chronic hypersensitivity and spinal cord NMDA receptor phosphorylation in a rat model of diabetic neuropathic pain. J Physiol 2010; 588: 4205-15.

28. Wadhwa A, Sengupta P, Durrani J, Akça O, Lenhardt R, Sessler DI, et al. Magnesium sulphate only slightly reduces the shivering threshold in humans. Br J Anaesth 2005; 94: 756-62.

29. McIntosh TK, Vink R, Yamakami I, Faden AI. Magnesium protects against neurological deficit after brain injury. Brain Res 1989; 482: 25260 . 